\title{
Conditioned reinforcement as a function of the intermittent pairing of a stimulus and a reinforcer
}

\author{
STEVEN L. COHEN \\ Bloomsburg State College, Bloomsburg, Pennsylvania 17815
}

\begin{abstract}
Pigeons' responses were maintained under a multiple schedule of conditioned and unconditioned reinforcement. Responses in the first component produced food according to a randominterval (RI) 90-sec schedule. Each food presentation was preceded by a brief stimulus. In this condition, the ratio of brief-stimulus to food presentations was $1: 1$, as the brief stimulus was continuously paired with food. In other conditions, responses in the first component also produced the brief stimulus unaccompanied by food, according to an independent RI 90-sec or RI 30-sec schedule. In these conditions, the brief stimulus was intermittently paired with food according to 2:1 and 4:1 ratios, respectively. Responses in the second component produced only the brief stimulus, according to a fixed-ratio schedule. Response rate in the second component was highest when the ratio of brief-stimulus to food presentations in the first component was $1: 1$, intermediate when the ratio was $2: 1$, and lowest when the ratio was $4: 1$, indicating a gradient of conditioned reinforcement strength. These data are consistent with some early experiments that used extinction procedures to test the hypothesis that intermittent pairing of a stimulus and a reinforcer generates a conditioned reinforcer weaker than one produced by continuous pairing.
\end{abstract}

One view of conditioned reinforcement is that a stimulus acquires its reinforcing properties through a process of classical conditioning (Hull, 1943; Pavlov, 1927). One way to test this hypothesis would be to show that variables affecting performance in classical conditioning also affect the strength of conditioned reinforcement (cf. Mackintosh, 1974). For example, a finding in classical conditioning has been that the continuous pairing of a conditioned stimulus with an unconditioned stimulus produces faster acquisition and/or greater asymptotic strength of a conditioned response than does intermittent pairing (e.g., Fitzgerald, 1963; Grant \& Schipper, 1952). Based on these findings, it would be expected that intermittent pairing of a stimulus and reinforcer would also weaken condition reinforcement strength. Indeed, the information hypothesis of conditioned reinforcement (Egger \& Miller, 1962) also predicts greater conditioned reinforcement strength with continuous pairing, since a stimulus is a more reliable predictor of food when it is continuously paired with food then when it is intermittently paired.

Based on these predictive results, several investigators have attempted to show that intermittent pairing of a stimulus with a reinforcer does produce decrements in conditioned reinforcement. Unfortunately, these experiments have produced inconsistent findings (see Nevin, 1973). Some studies have shown that intermittent pair-

Reprints may be obtained from S. L. Cohen, Department of Psychology, Bloomsburg State College, Bloomsburg, Pennsylvania 17815. ing does produce a conditioned reinforcer weaker than one produced with continuous pairing (D'Amato, Lachman, \& Kivy, 1958, Experiment 2; Mason, 1957). Other studies, however, have failed to find that intermittent pairing affects conditioned reinforcement (Melching, 1954) or have shown that intermittent pairing actually increases the strength of conditioned reinforcement (D'Amato et al., 1958, Experiment 1; Fox \& King, 1961; Klein, 1959; Saltzman, 1949).

It is difficult to pinpoint the source of these discrepant results because of the different methods used. An added problem was that these studies employed traditional extinction procedures, in which tests of conditioned reinforcement are conducted in the complete absence of unconditioned reinforcement. With these procedures, the conditioned reinforcing effects of a stimulus are often weak and transient, and tests of reinforcement sometime contain methodological problems (Kelleher \& Gollub, 1962). Most recent experiments in conditioned reinforcement use chained and brief-stimulus procedures in which conditioned reinforcement is examined while the pairing of the stimulus and reinforcer is maintained (see Fantino, 1977; Gollub, 1977).

In light of these inconsistent findings, I examined the effects of scheduling stimulus and reinforcer presentations using multiple schedules of conditioned and unconditioned reinforcement (Cohen, Calisto, \& Lentz, 1979; Cohen \& Lentz, 1976; Thomas, 1969). With these schedules, responses in one component of a multiple schedule produce food, and responses in the 
other component never produce food but, instead, produce a conditioned reinforcer. In the present study, the ratio of brief-stimulus to food presentations was varied in the first component of a multiple schedule, and the strength of conditioned reinforcement was determined by response rate in the second component. Specifically, responses in the first component always produced food according to a random-interval (RI) 90 -sec schedule of reinforcement, and each food presentation was preceded by a brief stimulus. Under this condition, the ratio of brief-stimulus to food presentations was $1: 1$, as the brief stimulus was continuously paired with food. In a second condition, responses in the first component also produced the brief stimulus unaccompanied by food according to an independent RI 90 -sec schedule. In this case, the brief stimulus was intermittently paired with food according to a $2: 1$ ratio. In a third condition, the "extra" brief stimuli were presented according to an independent RI 30 -sec schedule so that the ratio of brief-stimulus to food presentations was $4: 1$. In each condition, responses in the second component produced the brief stimulus according to a fixed-ratio (FR) schedule. It was expected that the highest response rate in the second component would be observed when the brief stimulus was continuously paired with food (1:1 ratio) and lowest when the brief stimulus was intermittently paired ( $4: 1$ ratio).

\section{METHOD}

\section{Subjects}

Six experimentally naive male White Carneaux pigeons were maintained at $80 \%$ of their free-feeding weights throughout the experiment.

\section{Apparatus}

The left key of a two-key pigeon chamber was used (Cohen et al., 1979; Cohen \& Lentz, 1976). A minimum force of .06 N operated the response key, which was transilluminated with red, white, or green light by an IEE one-plane readout. A $28-\mathrm{V}$ white houselight was located above and slightly to the right of the key. Grain was presented by a Lehigh Valley Electronics pigeon feeder that was illuminated white during the food cycle. Solid state circuitry (Coulbourn Instruments) controlled the sessions.

\section{Procedure}

Pigeons were trained to peck the red key for mixed grain. For 14 training sessions, an RI 6-sec schedule was gradually increased to an RI 60-sec schedule: The first peck on the red key after an average of $60 \mathrm{sec}$ turned off the keylight and presented $4 \mathrm{sec}$ access to grain. In the first condition, the RI 60-sec schedule was increased to RI 90-sec and food-paired brief-stimulus presentations were introduced. The first response after an average of $90 \mathrm{sec}$ turned the red key white and turned on the houselight for $1.5 \mathrm{sec}$. At the end of $1.5 \mathrm{sec}$, food was automatically delivered, and the brief stimulus remained on during the entire food cycle (i.e., preceding overlapping pairing; cf. Stubbs \& Cohen, 1972). In addition to the brief stimulus that accompanied food, some pigeons also received $1.5-\mathrm{sec}$ brief-stimulus presentations for pecks on the red key according to an independent, simultaneously operating RI $90-\mathrm{sec}$ or RI 30 -sec schedule. Thus, for pigeons that did not receive the "extra" brief stimuli
(Pigeons 60 and 70), the ratio of brief-stimulus to food presentations was $1: 1$. When the brief stimulus also occurred according to independent RI 90-sec (Pigeons 55 and 57) and RI 30-sec (Pigeons 53 and 61) schedules, the ratios were 2:1 and $4: 1$, respectively. If both food and brief-stimulus schedule requirements were satisfied, a response produced both events. Responses during brief-stimulus presentations had no scheduled effects, except that a response during a 1.5 -sec brief stimulus produced food if the RI 90-sec schedule requirement for food was satisfied. Sessions terminated after 45 food presentations and were conducted Monday through Friday.

In the second condition, a multiple schedule of conditioned and unconditioned reinforcement was put into effect. The contingencies in the first component were identical to those in Condition 1: That is, pecks on the red key produced food and brief-stimulus presentations. This component was in effect for $180 \mathrm{sec}$ and was followed by the red key turning green for 90 sec. Pecks in the green component never produced food but produced the brief stimulus according to an FR 10 schedule: The 10th response on the green key turned the key white and turned on the houselight for $4 \mathrm{sec}$. After $90 \mathrm{sec}$, the second component was terminated, and a $20 \mathrm{sec}$ time-out was in effect before the first component was reinstated. During the timeout, all lights in the chamber were turned off and responses had no effects. Sessions ended after 17 red-green cycles. If the 90 -sec green component timed out during a brief stimulus, the brief stimulus continued to time before the time-out was initiated. FRs partially completed in the green component counted toward completion of the FR 10 in the next green component. The RI schedules in the red component did not operate during the green component or the time-out period.

Each subject was exposed to six conditions of alternating RI and multiple RI FR schedules. The major independent variable

Table 1

Sequence of Conditions in Order of Occurrence and the Number of Sessions Under Each Condition

\begin{tabular}{|c|c|c|c|c|c|}
\hline \multicolumn{2}{|c|}{ Condition } & Sessions & \multicolumn{2}{|c|}{ Condition } & Sessions \\
\hline \multicolumn{3}{|c|}{ Pigeon 70} & \multicolumn{3}{|c|}{ Pigeon 60} \\
\hline RI & $1: 1$ & 21 & RI & $1: 1$ & 21 \\
\hline mult RI FR & $1: 1$ & 28 & mult RI FR & $1: 1$ & 26 \\
\hline RI & $4: 1$ & 7 & RI & $2: 1$ & 7 \\
\hline mult RI FR & $4: 1$ & 10 & mult RI FR & $2: 1$ & 14 \\
\hline RI & $2: 1$ & 7 & RI & $4: 1$ & 7 \\
\hline mult RI FR & $2: 1$ & 10 & mult RI FR & $4: 1$ & 10 \\
\hline \multicolumn{3}{|c|}{ Pigeon 57} & \multicolumn{3}{|c|}{ Pigeon 55} \\
\hline RI & $2: 1$ & 21 & RI & $2: 1$ & 21 \\
\hline mult RI FR & $2: 1$ & 23 & mult RI FR & $2: 1$ & 28 \\
\hline RI & $1: 1$ & 7 & RI & $4: 1$ & 7 \\
\hline mult RI FR & $1: 1$ & 12 & mult RI FR & $4: 1$ & 16 \\
\hline RI & $4: 1$ & 7 & RI & $1: 1$ & 7 \\
\hline mult RI FR & $4: 1$ & 10 & mult RI FR & $1: 1$ & 10 \\
\hline \multicolumn{3}{|c|}{ Pigeon 61} & \multicolumn{3}{|c|}{ Pigeon 53} \\
\hline RI & $4: 1$ & 21 & RI & $4: 1$ & 21 \\
\hline mult RI FR & $4: 1$ & 25 & mult RI FR & $4: 1$ & 29 \\
\hline RI & $2: 1$ & 7 & RI & $1: 1$ & 7 \\
\hline mult RI FR & $2: 1$ & 13 & mult RI FR & $1: 1$ & 17 \\
\hline RI & $1: 1$ & 7 & RI & $2: 1$ & 7 \\
\hline mult RI FR & $1: 1$ & 10 & mult RI FR & $2: 1$ & 10 \\
\hline
\end{tabular}

Note-The ratios next to each condition represent the ratio of brief-stimulus to food presentations for responses on the red key. $A$ ratio of $1: 1$ indicates that responding produced only food according to an RI 90-sec schedule. Ratios of 2:1 and 4:1 indicate that responses also produced brief stimuli according to RI 90-sec and RI 30-sec schedules, respectively. 
was the ratio of brief-stimulus to food presentations for responses on the red key. Each pigeon was exposed to a different sequence of the three ratios used in the experiment $(1: 1,2: 1$, and $4: 1)$. Table 1 presents the sequence of conditions for each pigeon. Under the three simple RI schedules, sessions were arbitrarily conducted for 21,7 , and 7 days, respectively. Sessions under the multiple schedule were conducted until no consistent increases or decreases in response rate in the red and green components were observed for at least five consecutive sessions.

\section{RESULTS}

The index of conditioned reinforcement strength is response rate in the green component of the multiple schedule. Responses during brief stimuli were not included in response rate calculations. Figure 1 presents response rate in the green component during the three main conditions of the experiment. The first observation is that the brief stimulus reinforced responding for all subjects. Cumulative records (not presented) indicate that response patterns in the green component were characteristic of patterns observed under FR schedules of food presentation, that is, a pause after a brief stimulus followed by a high constant response rate (see Cohen et al., 1979; Cohen \& Lentz, 1976). The main point of Figure 1, however, is that, with the exception of Pigeon 57, response rate was highest when the ratio of brief-stimulus to food presentations in the red component was $1: 1$, intermediate when the ratio was $2: 1$, and lowest when the ratio was $4: 1$. This finding was observed regardless of the sequence of conditions each pigeon experienced. Although response rate under a 1:1 ratio was clearly the highest, several pigeons (e.g.,
Pigeon 60) showed only small differences in response rate between $2: 1$ and $4: 1$ ratios.

Figure 1 also shows response rate averaged for all six pigeons and indicates that the averaged data are representative of individual performances. A one-factor repeated-measures analysis of variance on mean response rate in the green component for the last five sessions of each condition revealed a significant difference among the three conditions $[\mathrm{F}(2,10)=8.08, \mathrm{p}<.01]$. A priori contrasts showed that response rate under the $1: 1$ ratio (mean $=11.2$ responses $/ \mathrm{min}$ ) was significantly greater than response rate under the $2: 1$ (mean $=6.6$ ) condition $[\mathrm{t}(10)=2.52, \mathrm{p}<.05]$ and under the $4: 1($ mean $=3.9)$ condition $[\mathrm{t}(10)=4.00, \mathrm{p}<.01]$. However, response rate under the $2: 1$ condition was not significantly different from rates under the $4: 1$ condition $[t(10)=1.48]$.

A 2 by 3 repeated-measures analysis of variance was performed on mean response rate in the red component for the last five sessions of each condition. The two factors were (1) conditions when the RI 90-sec schedule was in isolation and when it was in the multiple schedule and (2) the three brief-stimulus-to-food ratios. Although response rate was slightly higher on the RI 90-sec schedule when it was in one component of a multiple schedule, this effect was not statistically significant $[F(1,5)=1.96]$. The response rate during the RI schedule did not significantly differ as a function of the ratio of brief-stimulus-to-food presentations $[F(2,10)=4.06]$, nor was there a significant interaction between the two factors $[F(2,10)=.26]$. These results indicate that changes in response rate in the green component were
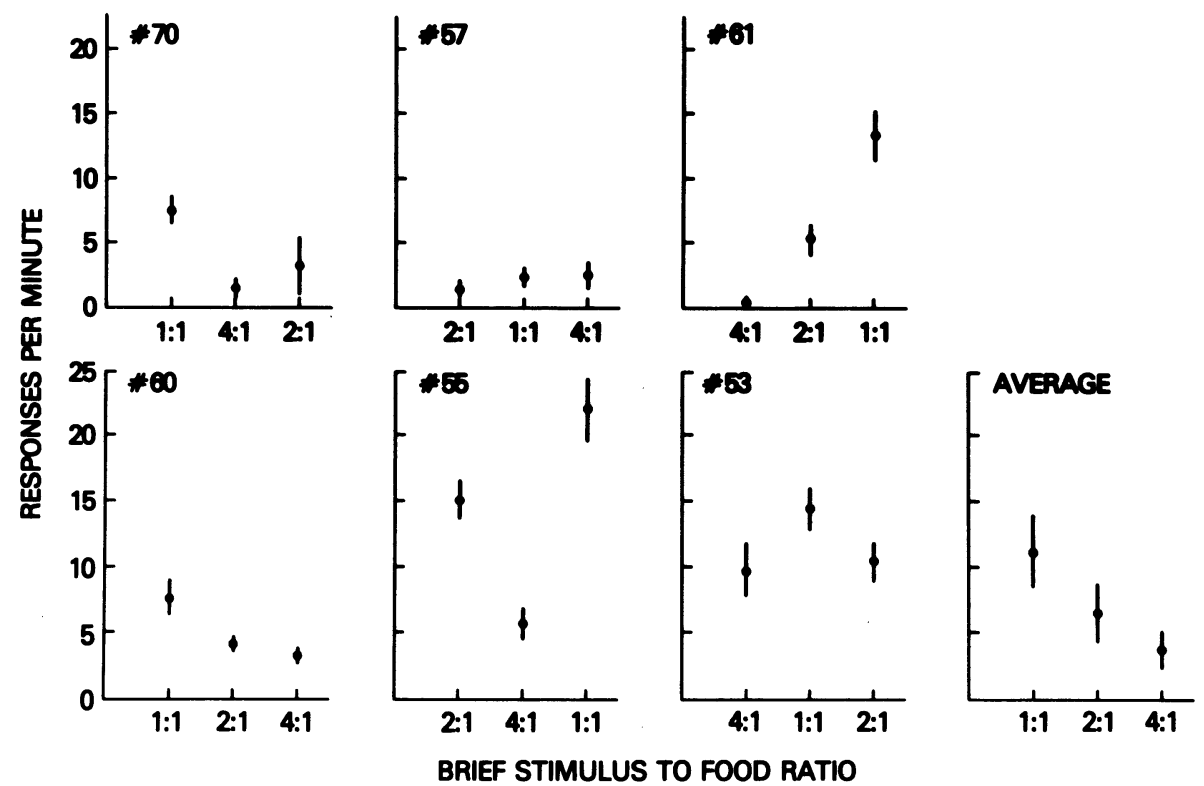

Figure 1. Response rate in the green component of the multiple schedule as a function of the ratio of brief-stimulus to food presentations. Responses produced brief stimuli according to an FR 10 schedule but never produced food. Data for individual subjects are means and standard errors for the last five sessions of each condition. The data at the right are means and standard errors averaged for all six pigeons. 
independent of concomitant changes in response rate in the red component.

\section{DISCUSSION}

The present study showed that intermittent pairing of a neutral stimulus with an unconditioned reinforcer produces decrements in the strength of conditioned reinforcement. The main finding of this experiment is that response rate in the second component of the multiple schedule was highest when the brief stimulus was continuously paired with food in the first component and lowest when it was intermittently paired. A type of gradient of conditioned reinforcement was apparent, with the highest response rate observed when the ratio of briefstimulus to food presentations was $1: 1$, intermediate when the ratio was $2: 1$, and lowest when the ratio was $4: 1$, although the differences in response rate between $2: 1$ and $4: 1$ ratios were not statistically significant.

These data are in agreement with those of D'Amato et al. (1958) and Mason (1957), who used extinction procedures to test the same hypothesis. In their experiments, rats were given differential reinforcement training in which one stimulus was paired with food on every trial and a second stimulus was partially paired. In a choice test, rats preferred to run to the side of a maze that contained the stimulus that was continuously paired with food. In the present study, pigeons were exposed to a single stimulus that was continuously paired in some conditions and partially paired in others, and the strength of conditioned reinforcement was measured by response rate rather than by preference.

In the present study, responding was maintained in the green component of the multiple schedule (although at different rates) with both continuous and intermittent pairing. These findings support data reported by Cohen et al. (1979), who examined responding under a similar reinforcement schedule. In their study, responding in the first component of the multiple schedule was maintained by a second-order schedule of reinforcement. Under the second-order schedule, pigeons completed a series of fixed-interval schedules, half of which irregularly ended in a brief stimulus plus food and half of which ended in the brief stimulus. Responding in the second component produced the brief stimulus according to an FR schedule. Responding was maintained at a low rate in the second component, even though the ratio of brief-stimulus to food presentations in the first component was $2: 1$. In a subsequent condition, the brief stimulus was omitted from the second-order schedule, except for the stimulus that accompanied food. In this condition, response rate in the second component increased for three of four birds. In the Cohen et al. (1979) study, it was impossible to determine if the increase in response rate was caused by the change from intermittent to continuous pairing of the brief stimulus and food or by an interaction of the inhibitory and excitatory properties of the brief stimulus. The present data suggest that the change to continuous pairing was responsible for the increased strength in conditioned reinforcement.

\section{REFERENCES}

Cohen, S. L., Calisto, G., \& Lentz, B. E. Separating the reinforcing and discriminative properties of brief-stimulus presentations in second-order schedules. Journal of the Experimental Analysis of Behavior, 1979, 32, 149-156.

Cohen, S. L., \& Lentz, B. E. Factors influencing responding under multiple schedules of conditioned and unconditioned reinforcement. Journal of the Experimental Analysis of Behavior, 1976, 26, 395-404.

D'Amato, M. R., Lachman, R., \& Kivy, P. Secondary reinforcement as affected by reward schedule and the testing situation. Journal of Comparative and Physiological Psychology, 1958, 51, 737-741.

Egger, M. D., \& Miller, N. E. Secondary reinforcement in rats as a function of information value and reliability of the stimulus. Journal of Experimental Psychology, 1962, 64, 97-104.

Fantino, E. Conditioned reinforcement: Choice and information. In W. K. Honig \& J. E. R. Staddon (Eds.), Handbook of operant behavior. Englewood Cliffs, N.J: Prentice-Hall, 1977.

Fitzgerald, R. D. Effects of partial reinforcement with acid on the classically conditioned salivary response in dogs. Journal of Comparative and Physiological Psychology, 1963, 56, 10561060.

Fox, R. E., \& King, R. A. The effects of reinforcementscheduling on the strength of a secondary reinforcer. Journal of Comparative and Physiological Psychology, 1961, 54, 260269.

GolluB, L. Conditioned reinforcement: Schedule effects. In W. K. Honig \& J. E. R. Staddon (Eds.), Handbook of operant behavior. Englewood Cliffs, N.J: Prentice-Hall, 1977.

Grant, D. A., \& Schipper, L. M. The acquisition and extinction of conditioned eyelid responses as a function of the percentage of fixed-ratio random reinforcement. Journal of Experimental Psychology, 1952, 43, 313-320.

Hull, C. L. Principles of behavior. New York: Appleton-CenturyCrofts, 1943.

Kelleher, R. T., \& Gollub, L. R. A review of positive conditioned reinforcement. Journal of the Experimental Analysis of Behavior, 1962, 5, 543-597.

KLEIN, R. M. Intermittent primary reinforcement as a parameter of secondary reinforcement. Journal of Experimental Psychology, 1959, 58, 423-427.

Mackintosh, N. J. The psychology of animal learning. London: Academic Press, 1974.

Mason, D. J. The relation of secondary reinforcement to partial reinforcement. Journal of Comparative and Physiological Psychology, 1957, 50, 264-268.

Melching, W. H. The acquired reward value of an intermittently presented neutral stimulus. Journal of Comparative and Physiological Psychology, 1954, 47, 370-373.

Nevin, J. A. Conditioned reinforcement. In J. A. Nevin \& G. S. Reynolds (Eds.), The study of behavior: Learning, motivation, emotion, and instinct. Glenview, Ill: Scott, Foresman, 1973.

Pavlov, I. P. Conditioned reflexes. London: Oxford University Press, 1927.

Saltzman, I. J. Maze learning in the absence of primary reinforcement: A study of secondary reinforcement. Journal of Comparative and Physiological Psychology, 1949, 42, 161-173.

StubBs, D. A., \& Cohen, S. L. Second-order schedules: Comparison of different procedures for scheduling paired and nonpaired brief stimuli. Journal of the Experimental Analysis of Behavior, 1972, 18, 403-413.

TномAs, J. R. Maintenance of behavior by conditioned reinforcement in the signaled absence of primary reinforcement. In D. P. Hendry (Ed.), Conditioned reinforcement. Homewood, Ill: Dorsey Press, 1969.

(Received for publication June 9, 1981.) 